\title{
The Impact of L2 Semantic Tasks (L2 Collocation versus L2 Definition) on Iranian Intermediate EFL Learners' Vocabulary Achievement
}

\author{
Mona Shamsi ${ }^{1}$, Ramin Rahimy ${ }^{2}$ \\ Department of English Language, Tonekabon Branch, Islamic Azad University, Tonekabon, IRAN \\ Monashams707@yahoo.com¹, Rahimy49@yahoo.com²
}

Received: November 29, $2016 \quad$ Accepted: February 3, 2017 Online Published: March 20, 2017

\begin{abstract}
This study investigated the relationship between teaching L2 semantic tasks (collocation vs. definition) in vocabulary achievement of Iranian intermediate English as a Foreign Language (EFL) learners. To this end, 60 students at intermediate level studying in the Simin Institute were selected from a total number of 100 participants based on their performance on Oxford Placement Test (OPT). After ensuring the criterion of homogeneity, they were randomly assigned to two experimental and one control group each comprising 20 participants. Before starting the treatment, a pretest was administered to find out learners' vocabulary knowledge. Then the experimental groups were instructed to use collocation and definition in vocabulary learning for 5 sessions while the control group received no treatment. After the end of the treatment, the same pre-test was administered to all groups as a post-test. Analysis of the results of three paired sample T-test and a one way ANOVA showed that the experimental group that received collocation task outperformed the other two groups (control group and second experimental group) in the post-test. It was concluded that teaching collocation task had a positive effect on learners' vocabulary knowledge.
\end{abstract}

Keywords: semantic tasks, morphology, collocation, definition, vocabulary learning strategies

\section{Introduction}

Vocabulary is a fundamental basis of every sentence in every language. Knowing frequent words in learning English plays a crucial role in promoting learners' abilities in listening, speaking, reading, and writing. Waring (2002) emphasizes the importance of constructing a reliable body of vocabulary knowledge to learn another language linguistically and psychologically and without this reliable knowledge of vocabulary, little can be learned in a foreign language and also by structuring a magnificent vocabulary knowledge domain quite actively, one can be capable of functioning in that language completely.

Nation (2001) introduced three reasons for the importance of vocabulary skills. First, it is a necessary part of reading comprehension. Second, by vocabulary learning, learners can get more academic success. Third, it prepares success in life. Students' vocabulary knowledge can be developed through a variety of ways. They learn words from others such as parents, teachers, peers, and contexts. Moreover, they learn words through their knowledge of word parts by using resources such as dictionaries or glossaries.

\section{Theoretical Framework}

Vocabulary was seen, for the first time, as one of the most important aspects of second language learning when the reading method emerged. In this method, emphasis was placed on developing criteria for selecting vocabulary content. The reading method aimed primarily at facilitating reading skills by improving vocabulary knowledge. Intensive oral drills were seen as a means of reinforcing the learning of a target language, rather than analyzing it. This method later came to be known as Audiolingualism (Schmitt, 2000).

In other words, the emphasis on using the language for meaningful communication rather than grammatical gave birth to the Communicative Language Teaching approach (CLT). Though it was a meaning-based approach, vocabulary was given a "secondary status" that served as a support for issues of "functional language," such as how to make a request. There is an assumption in this approach that L2 vocabulary would take care of itself like L1 vocabulary (Schmitt, 2000). 


\section{Statement of the Problem}

Learners have always encountered situations in which their comprehension is impeded by a large number of difficult words. In order to help learners become good and efficient learners, teachers should encourage them to acquire vocabulary effectively, but in most cases, done traditionally; that is, learners memorize word meanings deliberately. Vocabulary is the most vital part in learning a foreign language. Vocabulary learning is considered as the basic step toward mastering a foreign language. Different approaches toward language learning have different views on vocabulary (Jesa, 2008).

Some language teaching methodologies have attached great importance to vocabulary learning and some others have abandoned it (Schmitt, 2000). In practice, grammar and pronunciation are at the heart of language learning while vocabulary is neglected in most foreign language classes (Farghal \& Obiedat, 1995; Fernández, Prahlad, Rubtsova, \& Sabitov, 2009). Currently, it is generally established that vocabulary learning is one of the critical elements both in acquiring one's native language and in learning a foreign language (Morra \& Camba, 2009).

Vocabulary learning is considered as a fundamental element to attain a high level of proficiency in the target language by some scholars (Boers \& Lindstromberg, 2008). It is believed that having a large and varied vocabulary is the sign of communicative competence and it is one of the central aspects of language learning (McCrostie, 2007). Furthermore, researchers, teachers, and others involved in foreign language learning are paying special attention to foreign language vocabulary acquisition $(\mathrm{Zu}, 2009)$.

Like grammar, vocabulary knowledge is one of the elements of language (Nation \& Waring, 1997). It should be seen as an essential part of learning a foreign language since it paves the way to communication. That is, even a sufficient knowledge of vocabulary alone could be enough for a relative degree of communication to occur (Wallace, 1982). Moreover, Celce-Murcia and Rosensweig (1989) have the same opinion that vocabulary should be accepted as a central element in language instruction from the beginning stages. They more ever confirm that having an adequate stock of vocabulary with a minimum number of structures usually helps the learner more not only in reading comprehension but also in attaining more efficient communication than having a perfect command of structures with an inadequate amount of vocabulary.

\section{Research Question}

This study aims to answer the following question:

Do L2 semantic tasks (L2 collocation vs. L2 definition) have an impact on Iranian intermediate EFL learners' vocabulary achievement?

\section{Hypothesis of the Study}

H0: L2 semantic tasks (L2 collocation vs. definition) do not have any effect on Iranian intermediate EFL learners' vocabulary achievement.

\section{Review of the Related Literature}

Schmidt (1994) believes that the vocabulary learning refers to the learning without intent to learn or as the learning of one thing, e.g. vocabulary, when the learner's primary objective is to do something else, to communicate. It is believed that having a large and varied vocabulary is the indicator of communicative competence and it is one of the important aspects of language learning (McCrostie, 2007).

Vocabulary is generally a matter of remembering, unlike e.g. learning grammar, which is a system based mainly on rules. To be able to teach as effectively as possible, it is important to know how students remember words and how long-term memory is organized (Thornbury, 2004). One of the important roles of the language teacher is to help their students find the easiest way of conveying new information into the already existing system of the mental lexicon (Thornbury, 2004).

Firstly repetition, yet what he means is repetition of encounters with a word e.g. in reading. Furthermore, he stresses the importance of retrieval and use of the new words. While practicing, learners should make decisions about words, e.g. match rhyming words or use new items to complete sentences. Moreover, personalizing in vocabulary practice has proved to be beneficial for remembering along with spacing which means that presentation of new vocabulary is divided into more widely separated sequences followed by repeated revision later on with gradually extending periods between them e.g. the end of the lesson, next lesson, next week, and so on (Thornbury, 2004). 
McCarthy (1992) and Thornbury (2004) suggest two general possibilities of arranging vocabulary presentation. The teacher provides the learners with the meaning of the words and then progresses to introduction of their forms or vice versa - the form is introduced first, followed up with illustration of the meaning. Thornbury (2004) believes that using real objects (called realia) or pictures or mime can help students explain the meaning of words. The same author continues that these means are especially appropriate for teaching elementary levels where many concrete objects are taught. These types of presentation are usually supplemented with the use of TPR (Total Physical Response), which is a technique where the teacher gives commands and students perform the actions.

Thornbury (2004) believes that the sound of words is one of the aspects influencing the organization of the mental lexicon. This is arranged by various drilling activities. From experience, songs and chants are very suitable for drills, providing rhythm, catchy rhymes, and an element of fun. He suggests introducing the written form of the word should follow not long after the presentation of the pronunciation. He claims that it is necessary to add new vocabulary into existing knowledge in the mental lexicon which is done by types of activities where students make judgements about words, e.g. matching, comparing etc. This mechanical practice is then followed by more open and communicative activities. This is often provided by various pair-work or group-work activities.

Rashtchi and Rezvani (2011) in their study about vocabulary learning strategies assume that vocabulary instruction has undergone many changes and this problem forced teaching programs to find ways which can help learners expand their vocabulary knowledge. They suggested that designing the vocabulary program of a course needs to make decisions about the situation in which the course occurs, it is necessary to decide what vocabulary items will be selected for teaching, how many words are vital for learners to know, and how those will be selected and presented.

According to Rashtchi and Rezvani (2011), one of the most problematic issues in the area of vocabulary instruction is the role of memory and maintenance of the vast scale of lexicon flowing into the learners' memory. They concluded that learning vocabulary is a systematic task that should be employed by learners for learning new words. As Fraser (1999) states, learners use a number of strategies when they encounter unfamiliar words while reading. Hence, learners can use different kinds of strategies to depict the most appropriate strategy compatible with their age, learning style, and background knowledge. In addition, utilizing vocabulary learning strategies in reading various texts will facilitate incidental learning. Hence, it is the responsibility of the teachers to seek for strategies that best suit their learners.

\section{Methods}

\subsection{Participants}

The participants in this study were selected from 10 English classes consisting of 100 EFL Intermediate learners in Simin Language Institute in Tonekabon, Iran. The subjects had a mean age of 20 and had been studying English as a foreign language at least for five years. Their level of English proficiency was determined on the basis of their scores on Oxford Proficiency Test. Finally, the participants were divided into two groups of experimental $(\mathrm{Gex}=40)$ and one control $($ Gcon $=20)$. Therefore, the final total number of the sample was 60 subjects.

\subsection{Materials and Procedures}

The instrument utilized before the treatment was Oxford Placement Test (OPT). It was originally intended to homogenize the research participants. 100 Iranian EFL learners with similar achievement levels in proficiency and vocabulary knowledge were selected. Then the subjects were given a pre-test and post-test (see Appendixes) that were developed to test student vocabulary and decoding skills as they relate to semantic tasks (collocation vs. definition).

One group of questions tested student knowledge of the definitions, other questions tested students understanding of collocations. Each group of tests consists of 20 multiple choice questions. Both the pre-test and post-test were identical in structure, number of questions, and type of questions. The reliability of the test was calculated through Cronbach Alpha formula ( $\mathrm{r}=0.71)$. The participants were given a pre-test with twenty multiple choice items.

There were four possible answers and students had to guess the correct answers. Students who guessed the correct meaning of the word received one point. The control group received L2 vocabulary via the existing method such as repetition. They followed their normal educational program and they were taught new vocabularies through existing method. The experimental groups received the treatment. One experimental group was taught new vocabularies through traditional way of vocabulary learning by using dictionary. They learned vocabularies by the help of their definition. The other experimental group learned vocabularies by their collocations.

The designed pre-test was administered to the two groups to elicit evidence in order to compare with the post-test results. The tests were paper and pencil tests and there were no technical instruments such as computer. The tests were 


\section{International Journal of Research in English Education}

given by the researchers and the time of the test was 30 minutes. After completing the treatment sessions, a post-test was administered. The control group received the same materials and the amount of time allotted to the learning in both groups was the same. The post-test results were gathered and compared with those of pre-test. The analysis of data was carried out through SPSS software.

\section{Data Analysis}

The results of the tests were analyzed through descriptive and inferential statistics methods. In other words, the scores of the tests were analyzed by using certain descriptive and inferential statistical techniques by using SPSS program.

\subsection{Results}

Table 1. Paired samples descriptive statistics between the pre-test and the post-test of the first experimental group of the study $\left(\mathrm{EX}_{1}\right)$

\begin{tabular}{llllll}
\hline & Mean & N & Std. Deviation & Std. Error Mean \\
\hline Pair 1 & Pre-test EX1 & 14.5000 & 20 & 1.82093 & .40717 \\
& Post-test EX1 & 16.7500 & 20 & 1.58529 & .35448 \\
\hline
\end{tabular}

As it is indicated in Table 1, the number of subjects participated in the study has been 20 in the first experimental group $\left(\mathrm{EX}_{1}\right)$ which received collocation task as a treatment. The mean for the pre-test of $\mathrm{EX}_{1}$ was shown to be 14.500 as compared to the mean for the post-test $\mathrm{EX}_{1}$ which was 16.750. The standard deviations obtained for the experimental group show more variability among the scores of pre-test rather than post-test scores. As a result of this fact, subjects' post-test score in the experimental group may be more homogenous after going under the treatment (vocabulary teaching as well as collocation task practice).

Table 2. Paired samples descriptive statistics between the pre-test and the

Post-test of the second experimental group of the study $\left(\mathrm{EX}_{2}\right)$

\begin{tabular}{llllll}
\hline & & Mean & N & Std. Deviation & Std. Error Mean \\
\hline Pair 1 & Pre-test EX2 & 13.3000 & 20 & 1.45458 & .32525 \\
& Post-test EX2 & 14.7500 & 20 & .91047 & .20359 \\
\hline
\end{tabular}

As it is indicated in Table 2, the number of subjects participated in the study has been 20 in the second experimental group $\left(\mathrm{EX}_{2}\right)$ which received definition task as a treatment. The mean for the pre-test of $\mathrm{EX}_{2}$ was shown to be 13.300 as compared to the mean for the post-test $\mathrm{EX}_{2}$ which was 14.750. The standard deviations obtained for the experimental group show more variability among the scores of pre-test rather than post-test scores. As a result of this fact, subjects' post-test score in the experimental group may be more homogenous after going under the treatment (vocabulary teaching as well as definition task practice).

Table 3. Paired samples descriptive statistics between the pre-test and the post-test of the control group of the study

\begin{tabular}{llllll}
\hline & Mean & N & Std. Deviation & Std. Error Mean \\
\hline Pair 1 & Pre-test CON & 12.4000 & 20 & 1.69830 & .37975 \\
& Post-test CON & 12.6500 & 20 & 1.89945 & .42473 \\
\hline
\end{tabular}




\section{International Journal of Research in English Education}

As it is indicated in Table 3, the number of subjects participated in the study has been 20 in the control group which received no task as a treatment. The mean for the pre-test CON (pre-test of the control group) was shown to be 12.400 as compared to the mean for the post-test CONT which was 12.650. The standard deviations obtained for the control group show more variability among the scores of pre-test CONT rather than post-test scores. As a result of this fact, subjects' post-test score in the experimental group may be more homogenous after going under the treatment (vocabulary teaching with existing method).

\subsection{Inferential Analysis of the Data}

The necessary data for the inferential analysis are indicated in the following table.

Table 4. Paired samples t-test results for the first experimental group $\left(\mathrm{EX}_{1}\right)$

\begin{tabular}{lcccccc} 
& Mean & SD & $\begin{array}{c}\text { Standard } \\
\text { Error }\end{array}$ & $\mathrm{t}$ & $\mathrm{df}$ & Sig.(2 tailed) \\
\hline Pair1 & 2.25 & .44 & .099 & 22.65 & 19 & .000 \\
Pre-test EX ${ }_{1-}^{-}$ & & & & & \\
Post-test EX & & & & &
\end{tabular}

Table 4 presents the results for the paired t-test for two sets of the learners' scores in the first experimental group $\left(\mathrm{EX}_{1}\right)$ in both pre- and post-test which received collocation task as vocabulary learning practice. The sig. value is smaller than 0.05 which means the difference is significant. The observed t value for this experimental group is 22.65 which is much higher than the critical t value (tcrit=2.045) with the level of significance of 0.05 and degree of freedom of 19. This rejects the null hypothesis.

Table 5. Paired samples t-test results for the second experimental group $\left(\mathrm{EX}_{2}\right)$

\begin{tabular}{lcccccc} 
& Mean & SD & $\begin{array}{c}\text { Standard } \\
\text { Error }\end{array}$ & t & df & Sig.(2 tailed) \\
\hline Pair1 & 1.45 & .75 & .169 & 8.54 & 19 & .000 \\
Pre-test EX $2^{-}$ & & & & & \\
Post-test EX $\mathrm{EX}_{2}$ & & & & &
\end{tabular}

Table 5 presents the results for the paired t-test for two sets of the learners' scores in the second experimental group $\left(\mathrm{EX}_{2}\right)$ in both pre- and post-test which received definition task as vocabulary learning practice. The sig. value is smaller than 0.05 which means the difference is significant. The observed t value for this experimental group is 8.54 which is higher than the critical $t$ value (tcrit=2.045) with the level of significance of 0.05 and degree of freedom of 19 . This rejects the null hypothesis.

Table 6. Paired samples t-test results for the control group

\begin{tabular}{lcccccc} 
& Mean & SD & $\begin{array}{c}\text { Standard } \\
\text { Error }\end{array}$ & t & df & Sig.(2 tailed) \\
\hline $\begin{array}{l}\text { Pair1 } \\
\text { Pre-test CONT- }\end{array}$ & & .71 & .160 & 1.56 & 19 & .000 \\
Post-test CONT & & & & & \\
\end{tabular}


Table 6 presents that the sig. value is smaller than 0.05 which means the difference is significant. The observed t value for the control group before and after using the existing method is 1.56 which is smaller than the critical $t$ value (tcrit=2.045) with the level of significance of 0.05 and degree of freedom of 19.

Table 7. One-way ANOVA

\begin{tabular}{lccccc}
\hline \multicolumn{2}{c}{ Sum of Squares } & df & Mean & F & Sig. \\
\hline Between Groups & 168.13 & 2 & 84.06 & 36.28 & .000 \\
Within Groups & 132.050 & 57 & 2.317 & & \\
Total & 300.183 & 59 & & &
\end{tabular}

Table 7 indicates the result of one-way ANOVA for the differences among participating groups. Table 7 displays that there was statistically significant differences among groups. (sig.=.000, sig.<0.05)

\section{Discussion}

Words are building blocks in a language. By learning the lexical items, we start to develop knowledge of the target language. Based on our experience of being a language learner, we seem to have no hesitation in recognizing the importance of vocabulary in L2 learning. Richards (1976) contends that knowing a lexical item includes knowledge of frequency, collocation, register, case relation, underlying forms, word association, and semantic structure. Nation (2001) applies the terms receptive and productive to vocabulary knowledge description covering all the aspects of what is involved in knowing a word. Form, meaning, and use are the three main parts at the most general level.

A review of the results provides a positive answer to the question of this study: Do L2 semantic tasks (L2 collocation vs. L2 definition) have an impact on Iranian intermediate EFL learners' vocabulary achievement? At the same time, it rejects the stated null hypothesis: L2 semantic tasks (L2 collocation vs. L2 definition) do not have any effect on Iranian intermediate EFL learners' vocabulary achievement. The mean scores of the control group showed only a modest improvement. In addition, given the differences found between the experimental and control groups, there appears to be an advantage to teaching using semantic tasks such as collocation and definition tasks. This study showed that the three groups are different, and given the higher mean values for the first experimental group that received collocation task in posttest, there is a clear indication that using collocation task training helped students acquire vocabulary better than regular methods.

Brown (1974) claims that collocational instruction helps language learners perceive multi-word items used in the speech and writing of native speakers. Nattinger and DeCarrio (1992) argue that collocations are at the very center of language learning and teaching and they can also help the teaching of speech, listening comprehension, reading, and writing. Haswell (1991) declared that employing repetitive fixed expressions indicates a particular maturity in writing while the absence of these expressions is a characteristic of novice writers. Moreover, it has been shown that collocation knowledge can influence students' general language proficiency (Nesselhauf, 2003).

A hypothesis about the effects of teaching vocabulary through semantic tasks like collocation and definition on Iranian EFL learners' vocabulary knowledge was proposed. In order to find whether there is any significant difference between the groups, the researchers chose three homogenous groups and investigated the effect of vocabulary learning through semantic tasks which is compared with result of teaching vocabulary in the context. It can be concluded that there was a significant difference between the participating groups; so it can be concluded that the null hypothesis is rejected. The results of this study reduce the problems of root learning. It helps students remember the definitions of new words easier. The findings of this study are also useful for teacher trainers to incorporate appropriate and practical techniques and strategies for the instruction of vocabulary learning.

\section{Limitations of This Study}

Like any other studies, this research has certain limitations. A number of variables may influence the generalizability of this study. The sample size in all the experimental and control groups makes the study less likely to be generalizable. The individuals who participated in this study were 60 , which is not enough to confidently generalize the results. While 


\section{International Journal of Research in English Education}

the fact that the same teacher taught all the experimental and control groups classes used in this study, the specificity of the location (Simin Institute) makes the study less likely to yield the same results in other areas.

Since the sample size was small, differences among individual students may lead to differences in test scores. For example, at various points during the teaching period, students may have been absent from the class during the time of some collocational tasks. The number of words selected to be worked on was limited because of practicality deliberations. Additionally, students may have different interests or educational background that can influence the findings of the study. So caution should be taken into consideration in generalizing the results.

Another research is needed to prove the generalizability of this study and to refine teaching strategies. Another area for further research would be to explore the duration and intensity of intervention to determine maximum effect. Teachers can try different amounts of time and intensity to determine what will best suit their particular students. Further experimental research is needed to establish a standardized model for teaching collocation tasks, that is, what teaching strategies are most suitable for teaching semantic tasks. One could, for instance, investigate using flash cards or using software in teaching etymology.

\section{Conclusion}

To summarize, the vocabulary learning through semantic tasks especially collocation task was shown to be effective. At the very beginning, the learners took proficiency test and the results showed that the learners had similar proficiency. In the next step, the scores of the pre-test were analyzed through t-test. The findings indicated that the learners started the study with similar vocabulary knowledge. At last, the learners took post-test of vocabulary test after five sessions. Their scores were put on SPSS software to analyze the results. The data analysis showed that there was a statistically significant difference between groups.

The findings of this study may encourage teachers who still believe in teacher-centered in language teaching and use the traditional verbal method of translation in their teaching to their viewpoints in favor of nonverbal method and more learner-centered approaches of teaching vocabulary. This motivates students to become independent in their studies. The results of this study can also be beneficial for EFL learners at different levels, elementary, intermediate, and advance levels.

The findings of this study can be used in learning of some language skills and sub-skills such as reading, writing, vocabulary, grammar, pronunciation, spelling, and so forth. The results of this study can also be valuable for syllabus designers and textbook writers. They can embody sections related to vocabulary strategies or semantic tasks into the materials they develop in order to help students infer the meaning of words.

\section{References}

Boers, F., \& Lindstromberg, S. (2008). How Cognitive Linguistics Can Foster Effective Vocabulary Teaching. In Boers, F., Lindstromberg, S. (eds) Applications of Cognitive Linguistics: Cognitive Linguistic Approaches to Teaching Vocabulary and Phraseology (1st ed). Berlin, Mouton de Gruyter.

Brown, D. (1974). Advanced Vocabulary Teaching: The Problem of Collocation. RELC Journal, 5(2), 1-11.

Celce-Murcia, M., \& Rosensweig, F. (1989). Teaching Vocabulary in the ESL Classroom. In Celce-Murcia, M., \& McIntosh, L. (eds) Teaching English as a Second or Foreign Language (1st ed). New York, Newbury House Publishers Inc.

Farghal, M., Obiedat, H. (1995). Collocations: A Neglected Variable in EFL. International Review of Applied Linguistics in Language Teaching, 33(4), 315-331.

Fernández, R. F., Prahlad, S. R. R., Rubtsova, E., \& Sabitov, O. (2009). Collocations in the Vocabulary English Teaching as a Foreign Language. Acimed, 19(6), 1-5.

Fraser, C. A. (1999). Lexical Processing Strategy Use and Vocabulary Learning through Reading. Studies in Second Language Acquisition, 21(2), 225-241.

Haswell, R. H. (1991). Gaining Ground in College Writing: Tales of Development and Interpretation. Dallas, TX: Southern University Press.

Jesa, M. (2008). Efficient English Teaching. New Delhi: APH Publishing Corporation.

Mccarthy, M. (1992). Vocabulary. Oxford: Oxford University Press. 


\section{International Journal of Research in English Education}

McCrostie, J. (2007). Examining Learner Vocabulary Notebooks. ELT Journal: English Language Teachers Journal, 61(3), 246-255.

Morra, S., \& Camba, R. (2009). Vocabulary Learning in Primary School Children: Working Memory and Long-Term Memory Components. Journal of Experimental Child Psychology, 104(2), 156-178.

Nattinger, J., \& DeCarrio, J. (1992). Lexical Phrases and Language Teaching. Oxford: Oxford University Press.

Nation, P., Waring, R. (1997). Vocabulary Size, Text Coverage, and Word Lists. InSchmitt, N., \& McCarthy, M. (eds) Vocabulary: Description, Acquisition, and Pedagogy (1st ed). Cambridge, Cambridge University Press.

Nation, I. S. P. (2001). Learning Vocabulary in Another Language. Cambridge: Cambridge University Press. Retrieved $\begin{array}{llll}\text { September } & 15, & 2016 & \text { from }\end{array}$ http://citeseerx.ist.psu.edu/viewdoc/download?doi=10.1.1.429.2059\&rep=rep1\&type=pdf

Nesselhauf, N. (2003). The Use of Collocations by Advanced Learners of English and Some Implications for Teaching. Applied Linguistics, 24(2), 223-242.

Rashtchi, \& Rezvani. (2011). Vocabulary Learning Strategies: Do They Help Iranian EFL Learners to Overcome Vocabulary Learning Difficulties? Islamic Azad University, North Tehran Branch.

Richards, J. C. (1976). The Role of Vocabulary Teaching. TESOL Quarterly, 10(1), 77-89.

Schmitt, N. (2000). Vocabulary in Language Teaching. Cambridge: Cambridge University Press. Retrieved September 15, 2016 from http://citeseerx.ist.psu.edu/viewdoc/download?doi=10.1.1.429.2059\&rep=rep $1 \&$ type=pdf

Thornbury, S. (2004). How to Teach Vocabulary. Essex: Pearson Education Limited.

Wallace, M. (1982). Teaching Vocabulary. London: Heinemann.

Waring, R. (2002). A Comparison of the Receptive and Productive Vocabulary Size of Some Second Language Learners. Appeared in Immaculate; the Occasional Paper at Notre Dame Seishin University. Retrieved from http//www1.harenet.ne.jp/ waring/papers/vocsize.html on 13 February 2008.

Zu, F. (2009). Using Lexical Approach to Teach Vocabulary. US-China Foreign Language, 7(8), 44-47.

\section{Appendix A}

\section{Oxford Placement Test (OPT)}

- In this section you must choose the word or phrase which best completes each sentence.

- For questions 1 to 20, mark one letter A, B, C, or D on your Answer Sheet.

1. I suggest we outside the stadium tomorrow at 8.30 .
A) meeting
B) meet
C) met
D) will meet

2. They spent a lot of time at the pictures in the museum.
A) looking
B) for looking
C) to look
D) to looking

3. He spent a long time looking for a tie which with his new shirt.
A) fixed
B) made
C) went
D) wore

4. Fortunately, .................. from a bump on the head, she suffered no serious injuries from her fall.
A) other
B) except
C) besides
D) apart

5. I've always you as my best friend.
A) regarded
B) thought
C) meant
D) supposed

6. The singer ended the concert . her most popular song.
A) by
B) with
C) in
D) as

7. Whether she's a good actress or not is a of opinion.
A) matter
B) subject
C) point
D) case 
8. The decorated roof of the ancient palace was up by four thin columns.
A) built
B) carried
C) held
D) supported

9. Don't make such a ..! The dentist is only going to look at your teeth.
A) fuss
B) trouble
C) worry
D) reaction

10. This form be handed in until the end of the week.
A) doesn't need
B) doesn't have
C) needn't
D) hasn't got

11. This newspaper report contained important information.
A) many
B) another
C) an
D) a lot of

12. Although our opinions on many things , we're good friends.
A) differ
B) oppose
C) disagree
D) divide

13. She came to live here a month ago.
A) quite
B) beyond
C) already
D) almost

14. If you make a mistake when you are writing, just it out with your pen.
A) cross
B) clear
C) do
D) wipe

15. Have you considered to London?
A) move
B) to move
C) to be moving
D) moving

16. It can be a good idea for people who lead an active life to increase their
A) upturn
B) input
C) upkeep
D) intake

17. You ought to take up swimming for the of your health.
A) concern
B) relief
C) sake
D) cause

18. James was not sure exactly where his best interests
A) stood
B) rested
C) lay
D) centered

19. Why didn't you that you were feeling ill?
A) advise
B) mention
C) remark
D) tell

20. He's still getting the shock of losing his job.
A) across
B) by
C) over
D) through

\section{Appendix B}

\section{Pretest-Posttest}

1. He spoke English with a French accent.
A) average
B) careless
C) widespread
D) pronounced

2. His new novel has met with acclaim.
A) careless
B) dreadful
C) great
D) pronounced

3. I don't like this at all. It's a really affair.
A) outside
B) ugly
C) unfair
D) dangerous

4. I hope to............ my own business one day.
A) do
B) have
C) make
D) perform

5. I don't many hobbies.
A) do
B) have
C) make
D) perform 


\section{International Journal of Research in English Education}

6. Many countries problems with obesity.
A) do
B) have
C) make
D) perform

7. I've finally got the score I need. Let's go and...
A) get mark
B) get started
C) get lost
D) get over

8. My husband and I .nearly five years ago.
A) got over
B) got divorced
C) got nowhere
D) got lost

9. Take when you attend a lecture or you will forget what you heard.
A) a look
B) a break
C) notes
D) a rest

10. I don't my physics homework yet.
A) do
B) perform
C) make
D) behave

11. Have you. a decision yet?
A) do
B) make
C) get
D) create

12. The children a mess in the kitchen.
A) did
B) made
C) got
D) prepared

13. If you park there, you will have to a five
A) pay
B) take
C) have
D) bring

14. Few people can. a secret.
A) have
B) keep
C) save
D) take

15. He still in touch with most of his school mates.
A) keeps
B) saves
C) takes
D) has

16. $\mathrm{He}$ no attention to my requests.
A) paid
B) took
C) had
D) looked

17. I a cough to catch her attention.
A) gave
B) paid
C) took
D) had

18. Although the doctors tried hard, they couldn't his life.
A) save
B) bring
C) take
D) keep

19. Do you. a diary?
A) keep
B) have
C) sake
D) take

20. They close to hitting each other.
A) came
B) took
C) brought
D) arrived 